\title{
Fundamental and application aspects of adsorption cooling and desalination
}

\author{
Bidyut Baran Saha ${ }^{1,2, *}$, Ibrahim I. El-Sharkawy ${ }^{2,3}$, Muhammad Wakil Shahzad ${ }^{4}, K_{\text {Kaw Thu }}^{5}$, Li \\ $\mathrm{Ang}^{5}$ and $\mathrm{Kim}$ Choon $\mathrm{Ng}^{4}$
}

\author{
${ }^{1}$ Kyushu University Program for Leading Graduate School, Green Asia Education Center, \\ Kasuga-koen 6-1, Kasuga-shi, Fukuoka 816-8580, Japan \\ ${ }^{2}$ International Institute for Carbon-Neutral Energy Research (WPI-I2CNER), Kyushu University, \\ 744 Motooka, Nishi-ku, Fukuoka 819-0395, Japan \\ ${ }^{3}$ Mechanical Power Engineering Department, Faculty of Engineering \\ Mansoura University, El-Mansoura 35516, Egypt \\ ${ }^{4}$ King Abdullah University of Science \& Technology, Water Desalination \& Reuse Center \\ (WDRC), Thuwal, Saudi Arabia. \\ ${ }^{5}$ Department of Mechanical Engineering, National University of Singapore, Singapore, \\ "Author to whom correspondence should be addressed, Tel: +81-92-583-7903, Fax: +81-92-583- \\ 8909 , \\ E-mail: saha.baran.bidyut.213@m.kyushu-u.ac.jp
}

\begin{abstract}
Adsorption (AD) cycle is recently pioneered for cooling and desalination applications. For water treatment, the cycle can be used to treat highly concentrated feed water, ranging from seawater, ground water and chemically-laden waste water. This paper presents a review of the recent development of $\mathrm{AD}$ cycle and its hybridization with known conventional cycles such as the MED and MSF. We begin by looking at the basic sorption theory for different adsorbentadsorbate pairs, namely (i) silica gel-water, (ii) the zeolite-water, (iii) parent Maxsorb III/ethanol,
\end{abstract}


(iv) $\mathrm{KOH}-\mathrm{H}_{2}$ surface treated Maxsorb III/ethanol, and (v) a metal organic framework (MOF) material namely, MIL-101Cr/ethanol.

We also present the basic $\mathrm{AD}$ cycle for seawater desalination as well as its hybridization with known conventional thermally-driven cycles for efficiency improvement. We demonstrate the water production improvement by 2-3 folds by hybridization in a pilot comprising a 3-stage MED and $\mathrm{AD}$ plant and the top-brine temperature $50^{\circ} \mathrm{C}$.

Keywords: adsorption cooling; adsorption desalination; exergy analysis; MOFs; thermal desalination

\section{Nomenclature}

$A \quad$ surface area of adsorbent $\left(\mathrm{m}^{2}\right)$

$b \quad$ the affinity constant $\left(\mathrm{kPa}^{-1}\right)$

$b_{o} \quad$ the affinity at the reference temperature $\left(\mathrm{kPa}^{-1}\right)$

$D \quad$ diffusivity $\left(\mathrm{m}^{2} \mathrm{~s}^{-1}\right)$

$D_{\text {so }} \quad$ pre-exponential constant $\left(\mathrm{m}^{2} \mathrm{~s}^{-1}\right)$

$E \quad$ adsorption characteristics parameter $\left(\mathrm{kJ} \mathrm{Kg}^{-1}\right)$

$E_{a} \quad$ activation energy $\left(\mathrm{kJ} \mathrm{kg}^{-1}\right)$

$F \quad$ fractional uptake (-)

$p \quad$ equilibrium pressure $(\mathrm{kPa})$

$p_{o} \quad$ saturated pressure $(\mathrm{kPa})$

$Q \quad$ isosteric heat of adsorption at zero fractional uptake $\left(\mathrm{kJ} \mathrm{kmol}^{-1}\right)$

$R \quad$ universal gas constant $\left(\mathrm{kJ} \mathrm{kmol}^{-1} \mathrm{~K}^{-1}\right)$

$R_{g} \quad$ gas constant $\left(\mathrm{kJ} \mathrm{kg}^{-1} \mathrm{~K}^{-1}\right)$ 
$R_{p} \quad$ particle radius (m)

$T \quad$ temperature (K)

$T_{o} \quad$ reference temperature $(\mathrm{K})$

$t \quad$ time (s) and parameter in Tóth isotherm (-)

$V \quad$ the adsorbent particle volume $\left(\mathrm{m}^{3}\right)$

$W \quad$ equilibrium adsorption uptake $\left(\mathrm{kg} \mathrm{kg}^{-1}\right)$

$w \quad$ instantaneous adsorption uptake $\left(\mathrm{kg} \mathrm{kg}^{-1}\right)$

Win initial uptake $\left(\mathrm{kg} \mathrm{kg}^{-1}\right)$

$W^{*} \quad$ reference adsorption capacity $\left(\mathrm{kg} \mathrm{kg}^{-1}\right)$

$W_{s} \quad$ saturated adsorption capacity $\left(\mathrm{kg} \mathrm{kg}^{-1}\right)$

$W_{o}$ maximum adsorption capacity $\left(\mathrm{kg} \mathrm{kg}^{-1}\right)$

$\varphi \quad$ constant temperature of Eq. (3)

\section{Introduction}

Water and cooling are two major needs for life continuation. Presently, about $36 \%$ of global population ( 2.5 billion people) live in water scarce regions, defined here as water consumption at $1000 \mathrm{~m}^{3}$ per capita per annum, yet contributing to $22 \%$ of the world's GDP ( 9.4 trillion USD). With a business-as-usual (BAU) of water productivity and medium GDP growth predictions, about $50 \%$ of the world's population and $45 \%$ of global GDP will be at severe risk from water stress by 2050. For example, the rapidly-developing countries such as China, India, etc., will face severe water scarcity as early as 2025 , limiting their economic growth of these countries and affecting about 2.7 billion people, as reported in a recent report from IFPRI-VEOLIA (2011) $[1,2]$. 
In the Gulf Cooperating Council (GCC) countries, a similar water scarcity situation is predicted. As seen in Figure 1, the annual per capita (APC) renewable water availability in the Gulf countries have decreased rapidly between 1962 and 2010; The reported APC of renewable water varied from a low value of $7.3 \mathrm{~m}^{3}$ in Kuwait, $20 \mathrm{~m}^{3}$ in UAE, $33 \mathrm{~m}^{3}$ in Qatar, $92 \mathrm{~m}^{3}$ in Bahrain to a higher value of $503 \mathrm{~m}^{3}$ of Oman. It is estimated that water demand in most of GCC countries will be tripled by 2020 from 2000 level as shown in Table 1 [3-6]. Many countries in the Gulf countries plan to invest significantly in the energy efficient and environment-friendly desalination processes in next five years: Over the past years, from 2005-2014, Kuwait spent USD 5.28 billion on water production whilst KSA has invested more than USD18 billion on new facilities.

Similarly, air-conditioning in GCC where summer temperature can be as high as $50^{\circ} \mathrm{C}$ is expensive necessity. In GCC, cooling consume up to $70 \%$ of annual-peak electricity production, around \$20 billion yearly fuel opportunity. If current trend persist, the cooling demand is estimated to be triple by 2030 and by then 1.5 million barrels of oil need to burn to run airconditioning facilities in GCC. In addition, GCC government will spend $\$ 100$ billion by 2030 for new cooling capacities and $\$ 120$ billion for new power capacities. Figure 2 shows cooling capacity growth in the GCC from 2010-2030 in millions of Rtonne [7].

From the viewpoint of water-cooling-energy-environment nexus, there is an urgent motivation for research and innovation in water \& cooling processes addressing three major issues; (i) lower specific energy consumption in terms of $\mathrm{kWh} / \mathrm{m}^{3}$ and $\mathrm{kW} /$ Rtonne (ii) utilization of low temperature heat of renewable and non-renewable sources, and (iii) lowering of pollutants in brine discharge as well as carbon dioxide emission of burned fossil fuels.

Adsorption (AD) systems are introduced for desalination and cooling. AD system can operate using low temperature waste heat and can produce water and cooling. In the past few decades, adsorption cooling systems using alternative refrigerants of CFCs, HCFCs and HFCs received a considerable attention due to the increasing awareness of Ozone depletion and global worming problems. Thermally powered adsorption systems have attractive features; (i) they have the ability to operate by low temperature driving heat sources typically below $100^{\circ} \mathrm{C}$, (ii) they are 
environmentally friendly as natural refrigerants such as water or ethanol can be used, and (iii) almost no electricity usage.

However, the main drawback of this technology is the low system performance in terms of cooling capacity and COP. The system performance can be improved by using promising adsorbent/refrigerant pairs with high adsorption capacity and fast kinetics. Extensive studies have been conducted to investigate adsorption isotherms of various pairs. Aristov et al. [8] measured adsorption kinetics of vapor on loose grains of Fuji Davison RD silica gel using TG differential method. Experiments have been conducted within a temperature range of $29-64^{\circ} \mathrm{C}$ and a pressure range from 6.5 to 34 mbar. El-Sharkawy et al. [9] investigated adsorption kinetics of activated carbon fiber/ethanol pair by gravimetric method using TGA (CAHN TG 2121) unit. The authors proposed a new concentration profile that removes the restrictions between the overall mass transfer coefficient and the diffusion time constant and the model has been validated experimentally. Adsorption kinetics of ammonia onto composite adsorbent material ( $\mathrm{BaCl}_{2}$ impregnated into a vermiculite matrix) has been investigated under isothermal conditions and in a laboratory scale system [10]. El-Sharkawy [11] addressed the effect of using classical Linear Driving Force (LDF) model on the performance evaluation of adsorption cooling systems. A comparative study between the LDF approximation and the Fickian diffusion (FD) model has also been presented.

In this paper, we presented basic sorption theory for different adsorbent-adsorbate pairs. The authors tested different pairs such as: (i) silica gel-water, (ii) the zeolite-water, (iii) parent Maxsorb III/ethanol, (iv) $\mathrm{KOH}-\mathrm{H}_{2}$ surface treated Maxsorb III/ethanol, and (v) a metal organic framework (MOF) material namely, MIL-101Cr/ethanol. We also presented basic AD cycle operation and its integration with the conventional multi effect desalination MED stages to exploit the thermodynamic synergy of the thermally-driven processes with temperature cascade. Such a hybrid process, called MEDAD and MEAD cycles, overcome the limitations of conventional MED system by having its bottom brine temperature operating below the ambient. In addition, we presented the predictions of simulation and experimental data of a MEDAD pilot, comprising only 3 stages of MED with a basic 4-bed AD. 


\section{Adsorbent-adsorbate pair testing}

In this section, adsorption characteristics of ethanol onto several promising adsorbents were measured by a magnetic suspension adsorption measurement unit. The studied adsorbents are parent Maxsorb III, KOH-H2 surface treated Maxsorb III and a metal organic framework (MOF) material namely, MIL-101Cr. The experiment was conducted using the multi-step technique.

In each step adsorption temperature was kept constant and evaporation temperature increased step by step until reaching relative pressure of about 0.9. Prior to each adsorption isotherm measurement, the sorbent was first heated at $120^{\circ} \mathrm{C}$ for 4 hours under vacuum condition of $3 \times 10^{-4} \mathrm{~Pa}$ to remove any adsorbed gas from the sample. As the weight measurement is affected by the buoyancy force, the effect of buoyancy is considered during measurements. An isothermal air bath is used to avoid the condensation inside the connecting tubes setting the bath temperature $20^{\circ} \mathrm{C}$ higher than the saturation temperature of the vapor. The schematic diagram of the experimental apparatus is shown in Figure 3. A detailed description of the experimental procedure can be found elsewhere $[12,13]$.

\subsection{Adsorption isotherms and kinetics}

Figures 4 and 5 show the plot of adsorption isotherms of parent Maxsorb III/ethanol and KOH$\mathrm{H}_{2}$ treated Maxsorb III/ethanol pairs, respectively. The Dubinin-Astakhov equation (Eq. 12) is used to fit adsorption isotherms of both pairs. Experiments have been conducted within adsorption temperature ranging from 30 to $70^{\circ} \mathrm{C}$. For each isotherm, the relative pressure changes from 0.1 to about 0.9 .

$$
\begin{aligned}
& W=W_{0} \exp \left\{-\left(\frac{A}{E}\right)^{n}\right\} \\
& A=R_{g} T \ln \left(\frac{P_{s}}{P}\right)
\end{aligned}
$$

Numerical values of $W_{o}, n$ and $E$ for parent Maxsorb III/ethanol pair are found to be $1.2 \mathrm{~kg} \mathrm{~kg}^{-1}$, 1.8 and $140 \mathrm{~kJ} \mathrm{~kg}^{-1}$, respectively. For $\mathrm{KOH}-\mathrm{H}_{2}$ treated Maxsorb III/ethanol pair, these values are $1.0 \mathrm{~kg} \mathrm{~kg}^{-1}, 1.9$ and $152 \mathrm{~kJ} \mathrm{~kg}^{-1}$.

It can be seen from Figures 4 and 5 that adsorption capacity of Maxsorb III is higher than that of $\mathrm{KOH}-\mathrm{H}_{2}$ treated Maxsorb III. However, the adsorption kinetics is also an important issue. 
Figure 6 shows the adsorption isotherms of MIL-101Cr/ethanol pair for adsorption temperatures range from 30 to $70^{\circ} \mathrm{C}$. It can be seen from Figure 6 that the adsorption capacity of MIL$101 \mathrm{Cr} /$ ethanol pair is as high as $1.1 \mathrm{~kg} \mathrm{~kg}^{-1}$ at adsorption temperature of $30^{\circ} \mathrm{C}$. It is also visible from Figure 6 that the adsorption capacity increases with the increase of relative pressure until it reaches 0.3 or 0.4 . After that the increase in adsorption capacity is only marginal. Tóth equation (Eq. 3) is used to fit the adsorption isotherms of the studied pair [14].

$$
W=W_{s} \frac{b p}{\left[1+(b p)^{t}\right]^{\frac{1}{t}}}
$$

where,

$$
\begin{gathered}
b=b_{o} \exp \left(\frac{Q}{R T}-\frac{Q}{R T_{o}}\right) \\
W_{s}=W^{*} \exp \left(\varphi\left(1-\frac{T}{T_{o}}\right)\right)
\end{gathered}
$$

In the above equations, $W$ is the adsorption equilibrium uptake, $W_{s}$ presents the saturated adsorption capacity whilst $W^{*}$ is the reference adsorption capacity. In this study, the reference temperature is considered as $303 \mathrm{~K}$. The parameters $b$ is the affinity constant and $b_{o}$ represents the affinity at the reference temperature. The term, $\varphi$, is a constant temperature, and $Q$ is the measure of isosteric heat of adsorption at zero fractional uptake. The numerical values of $W^{*}, b_{o}$, $Q / R T_{o}$ and $\varphi$ are found to be $1.15,0.342,2.193,17.845$ and 0.358 , respectively.

Temporal histories of adsorption uptake and pressure of MIL-101Cr/ethanol pair at adsorption temperature of $50^{\circ} \mathrm{C}$ are depicted in Figure 7. At each adsorption step, adsorption uptake increases continuously until reaches the equilibrium condition corresponding to adsorption temperature and evaporator pressure. Similar trends have also been found for the parent Maxsorb $\mathrm{III} /$ ethanol and $\mathrm{KOH}-\mathrm{H}_{2}$ treated Maxsorb III/ethanol pairs. Considering a spherical adsorbent particle shape, the Fickian diffusion model (Eq. 6) is used to estimate the adsorption kinetics of assorted adsorbent/refrigerant pairs. Solution of equation (6) gives the familiar expression (Eq. 7) below [11].

$$
\frac{\partial w}{\partial t}=\frac{1}{r^{2}} \frac{\partial}{\partial r}\left(r^{2} D \frac{\partial w}{\partial r}\right)
$$




$$
F=\frac{w-w_{i n}}{W-w_{i n}}=1-\frac{6}{\pi^{2}} \sum_{n=1}^{\infty} \frac{1}{n^{2}} \exp \left(-\frac{n^{2} \pi^{2} D t}{R_{p}^{2}}\right)
$$

Equation (7) can be then simplified into Eq. (8) and Eq. (9) at long and short adsorption times, respectively $[12,13]$.

$$
\begin{gathered}
F=\frac{w-w_{\text {in }}}{W-w_{\text {in }}}=1-\frac{6}{\pi^{2}} \exp \left(-\frac{\pi^{2} D t}{R_{p}^{2}}\right) \\
\frac{w}{W} \approx \frac{2 A}{V}\left(\frac{D t}{\pi}\right)^{1 / 2}
\end{gathered}
$$

Diffusion time constants of $\mathrm{KOH}-\mathrm{H}_{2}$ surface treated Maxsorb III/ethanol pairs are evaluated using Eq. (8) whilst the semi-infinite model (Eq. 9) is found to be more suitable to estimate the diffusion time constant of MIL-101Cr/ethanol pair. The average values of diffusion time constant at each isotherm is calculated and a plot of $\ln \left(D / R_{p}{ }^{2}\right)$ versus the inverse of adsorption temperature $(1 / T)$, Arrhenius plot, for the studied adsorbent/refrigerant is shown in Figure 8. It can be seen from Fig. 8 that the diffusion time constants of MIL 101Cr/ethanol pair is strongly depends on adsorption temperatures in comparison with carbon based adsorbents + ethanol pairs.

\section{AD cycle for desalination}

The basic AD operation involves two main processes namely; i) adsorption-assisted-evaporation and ii) desorption-activated-condensation. In first half cycle, vapors generated in AD evaporator are adsorbed on the pore surface area of adsorbent. The heat source is circulated through the tubes of evaporator and seawater is sprayed on the tube bundle. It is observed that the evaporation is initiated by heat source but during adsorption process the high affinity of water vapor of adsorbent drop the evaporator pressure and contribute in evaporation. The AD evaporator operation temperature can be controlled by heat source temperature that is normally circulated in term of chilled water. The AD evaporator can operate at a wide range of chilled water temperature varies from $5^{\circ} \mathrm{C}$ to $30^{\circ} \mathrm{C}$ to produce the desalination and cooling effects. The vapor adsorption process is continues until the adsorbent bed reach to a saturation state.

During desorption-activated-condensation process saturated adsorbent is regenerated using the low grade industrial waste heat or renewable energy (desorption temperature varies from $55{ }^{\circ} \mathrm{C}$ to $85{ }^{\circ} \mathrm{C}$ ) and desorbed vapors are condensed in a water cooled condenser and collected as a distillate water. It can be seen that two useful effects produced by AD cycle are the cooling effect 
by the first process "adsorption-assisted-evaporation" and fresh water by converting the seawater by second process "desorption-activated-condensation". Useful effects which are cooling and water production can be produced simultaneously by introducing the multi-bed technique.

From energy efficiency, the AD cycle [15-38] is deemed inefficient for desalination in the basic cycle configuration as the latent heat of evaporation is large, typically it consumes more than 640 $\mathrm{kWh} / \mathrm{m}^{3}$. To achieve an energy efficiency of less than $15 \mathrm{kWh} / \mathrm{m}^{3}$, the latent energy of evaporation/condensation must be recycled for more than 40 times. For this purpose, the AD technology is the enabler technology for integrating it to the proven thermally-driven desalination cycles such as the MED or MSF. With hybridization, it exploits the thermodynamic synergy between the thermally-driven cycles to give better temperature differentials across each $\mathrm{MED} / \mathrm{MSF}$ stages and such synergetic effect is delivered by lowering of the bottom brine temperature, to even below the ambient. It is a fact that the lowest temperature differential need to effect evaporation and condensation is about $2 \mathrm{~K}$ (inclusive of the saline concentration elevation effect), the total temperature difference (DT) needed is $80 \mathrm{~K}$. To achieve a DT $>80 \mathrm{~K}$, designers of conventional cycles MED cycles have to innovative process breakthrough: Firstly, the top-brine temperature (TBT) have to be raised than the existing limit of $70^{\circ} \mathrm{C}$, and secondly, the bottom brine temperature (BBT) has to be lowered to below ambient, typically as low as $10^{\circ} \mathrm{C}$. To elevate the TBT without having severe fouling and corrosion effects, Hamad et al [39]

have experimented the use of Nano-filtration (NF) as a pre-treatment of seawater feed. The dissolved ions in the heated brine that are responsible for 'soft-scales' formation, namely, $\mathrm{Ca}++$, $\mathrm{Mg}++$, etc., but when removed sufficiently prior to supplying to the MED, it enables the TBT to be raised up to a temperature of $120^{\circ} \mathrm{C}$ without having excessive scaling on the heat transfer surfaces. Coupling the NF and AD processes enable the DT in a MED design to exceed the minimum of $80 \mathrm{~K}$, and hence the specific energy consumption of seawater desalination can be lowered to less than $15 \mathrm{kWh} / \mathrm{m}^{3}$.

\section{The Hybrid MEDAD Pilot}

MEDAD is a hybrid of conventional MED and an AD cycle. In MED stages, vapor emanation from feed seawater is achieved by falling film-evaporation process. Evaporation energy is recovered by series of re-utilization of vapor condensing energy in successive stage those are 
produced in preceding stages. Process of vapor production and energy recovery by condensation continues until the last stage of MED. The vapors from the last stage are than directed towards $\mathrm{AD}$ beds where they adsorbed on the adsorbent surface. Adsorbent high affinity for water vapor drops the pressure and hence the saturation temperature of last stages below ambient typically up to $5^{\circ} \mathrm{C}$. The $\mathrm{AD}$ integration with last stage of MED help to extend operational temperature range from $40^{\circ} \mathrm{C}$ to $5^{\circ} \mathrm{C}$, help to insert more number of stages results higher system performance ratio.

For demonstration of MEDAD cycle, an experimental test facility is fabricated that integrate a 4bed AD cycle to a 3-stage MED, and the cycle is called MEDAD in short, as shown in Figure 9. In the hybrid system, the vapour emanating from the last stage of MED is sent to the evaporator of the AD cycle, enabling a direct uptake of vapour by the adsorbent in the AD beds. This hybrid cycle lowers the BBT of conventional MED system to below the ambient temperature. Detail of hybrid MEDAD cycle can be found in the literature [40-47].

\section{Results and Discussion}

Figure 10 shows the temperature profiles of system components during conventional MED and hybrid MEDAD operation at heat source $50^{\circ} \mathrm{C}$. It can be seen that during MED operation inter stage temperature difference varies $1-1.2^{\circ} \mathrm{C}$. Once the integration valve of MED and AD is opened to operate as a hybrid MEDAD the inter stage temperature difference $(\Delta \mathrm{T})$ increased to $4-5^{\circ} \mathrm{C}$. This higher inter stage $\Delta \mathrm{T}$ increase the heat flux and hence the evaporation rate. $\mathrm{AD}$ cycle desorption heat was supplied at $80^{\circ} \mathrm{C}$ with 300 second half cycle during hybrid cycle operation. AD cycle parameters $\left(80^{\circ} \mathrm{C}\right.$ and 300 second half cycle) were optimized after several experiments. These parameters can effect system performance in terms of long desorption time if heat source temperature is low and adsorption rate if cycle time is too short.

Figure 11 shows the water production profiles of MED and hybrid MEDAD systems at $50^{\circ} \mathrm{C}$. It can be seen clearly that water production boosted 2-3 folds once MED is integrated with AD. The main reason for this production boost is higher inter stage $\Delta \mathrm{T}$ due to AD pulling effect that increase the heat flux and hence the evaporation rate. 
Experiments were conducted at different heat source temperatures varies from 15 to $70^{\circ} \mathrm{C}$ to track system performance and water production boost form 2-3 times were observed at all heat source temperatures. The conventional MED system cannot be operated below $38^{\circ} \mathrm{C}$ due to ambient temperature limitations but MEDAD has no limitations and last stage can be as low as $5^{\circ} \mathrm{C}$.

\section{Conclusions}

Adsorption isotherms and kinetics of three promising adsorbent/refrigerant pairs have been measured gravimetrically using a magnetic suspension adsorption measurement unit. The studied pairs are parent Maxsorb III/ethanol, $\mathrm{KOH}-\mathrm{H}_{2}$ treated Maxsorb III/ethanol and MIL$101 \mathrm{Cr} /$ ethanol. Experimental results show that, the maximum adsorption capacity of parent Maxsorb III/ethanol pair is as high as $1.2 \mathrm{~kg} \mathrm{~kg}^{-1}$ whilst MIL-101Cr/ethanol and $\mathrm{KOH}-\mathrm{H}_{2}$ treated

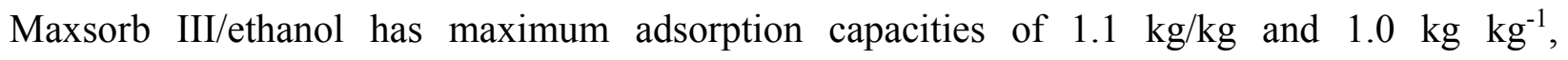
respectively. It is also found that, the Fickian diffusion model can fairly present adsorption kinetics of assorted adsorbent/refrigerant pairs. Recent development in adsorption desalination (AD) and conventional MED desalination cycles have been also reviewed in this paper. The key role of AD cycle has been hybridized with the proven cycles such as the MED cycle, exploiting the thermodynamic synergy between the thermally-driven cycles that significantly improve the water production yields. Experiments were conducted in a lab-scale pilot MEDAD and confirmed the excellent synergetic effects that boosted the water production up to 2-3 folds over the conventional MED.

\section{Acknowledgments}

The authors wish to thank National Research Foundation (NRF) Singapore (grant WBS no. R265-000-399-281), King Abdullah University of Science \& Technology (KAUST) (Project no. 7000000411) and Japan Science and Technology Agency (JST), Core Research Evolution Science and Technology (CREST) for financial support for this project. 


\section{References:}

1. Sustaining growth via water productivity: $2030 / 2050$ scenarios http://growingblue.com/wp-content/uploads/2011/05/IFPRI VEOLIA STUDY 2011.pdf

2. http://www.desdemonadespair.net/2009 1101 archive.html.

3. Abramovitz, Janet. (1996, March). Imperiled waters, impoverished future: The decline of freshwater ecosystems (Worldwatch Paper No. 128). Washington, DC: Worldwatch Institute.

4. http://www.un.org/waterforlifedecade/scarcity.shtml

5. Don Hinrichsen and Henrylito Tacio, The Coming Freshwater Crisis is Already Here. (http://www.wilsoncenter.org/sites/default/files/popwawa2.pdf)

6. Marcoux, A.Population and water resources. Rome: FAO, 1994.

7. Unlocking the Potential of District Cooling: The need for GCC governments to take action, a report by Booz \& Company in 2012.

8. Y.I. Aristov, M.M. Tokarev, A. Freni, I.S. Glaznev, G. Restuccia, Kinetics of water adsorption on silica Fuji Davison RD, Microporous Mesoporous Mater 96 (2006) 65-71.

9. I.I. El-Sharkawy, B.B. Saha, S. Koyama, K.C. Ng, A study on the kinetics of ethanolactivated carbon fiber: Theory and experiments, Intnational Journal of Heat and Mass Transfer, 49 (2006) 3104-3110.

10. Y. Zhong, R.E. Critoph, R.N. Thorpe, Z. Tamainot-Telto, Dynamics of $\mathrm{BaCl}_{2}-\mathrm{NH}_{3}$ adsorption pair, Applied Thermal Engineering, 29 (2009) 1180-1186.

11. I.I. El-Sharkawy, On the linear driving force approximation for adsorption cooling applications, International Journal of Refrigeration, 34 (2011) 667-673.

12. I.I. El-Sharkawy, K. Uddin, T. Miyazaki1, B.B. Saha, S. Koyama, J. Miyawaki and S.H. Yoon, Adsorption of ethanol onto parent and surface treated activated carbon powders, International Journal of Heat and Mass Transfer, 73 (2014) 445-455.

13. B.B. Saha, I.I. El-Sharkawy, T. Miyazaki, S. Koyama, S.K. Henninger, A. Herbst, C. Janiak, Ethanol adsorption onto metal organic framework: Theory and experiments, Energy, Vol. 79, pp. 363-370, 2015. 
14. D.D. Do, Adsorption Analysis: Equilibria and Kinetics, Imperial College Press,1998.

15. B.B. Saha, A. Akisawa, T. Kashiwagi, Solar waste heat driven two-stage adsorption chiller: the prototype, Renewable Energy, 23 (2001) 93-101.

16. K.C. Ng, K. Thu, B.B. Saha and A. Chakraborty, "Study on a waste heat-driven adsorption cooling cum desalination cycle", International Journal of Refrigeration, 35 (3) (2012) 685-693, 2012.

17. K. Thu, B.B. Saha, A. Chakraborty, W.G. Chun and K.C. Ng, Study on an advanced adsorption desalination cycle with evaporator-condenser heat recovery circuit, International Journal of Heat and Mass Transfer, 54 (1-3) (2011) 43-51.

18. B.B. Saha, I.I. El-Sharkawy, Next generation thermally powered adsorption refrigeration cycles, VIII Minsk International Seminar Heat Pipes, Heat Pumps, Refrigerators, Power Sources, Keynote Paper, pp. 52-63, Minsk, Belarus, 2011.

19. Wang, A. Chakarborty, K.C. Ng, B.B. Saha, How heat and mass recovery strategies impact the performance of adsorption desalination plant: Theory and experiments, Heat Transfer Engineering, 28 (2007) 147-153.

20. B.B. Saha, n.k. Choon, A. Chakarborty, K. thu, Desalination System and Method, in: W.P. WO2011010205A1 (ed.), 2011.

21. K. Thu, Adsorption desalination: Theory \& Experiments in: Doctoral Thesis, National University of Singapore, 2010.

22. B.B. Saha, K.C.A. Alam, A. Akisawa, T. Kashiwagi, K.C. Ng, H.T. Chua, Two-stage nonregenerative silica gel-water adsorption refrigeration cycle, American Society of Mechanical Engineers, Advanced Energy Systems Division (Publication) AES, 40 (2000) 65-69.

23. K. Thu, Y. D. Kim, M. W. Shahzad, J. Saththasivam and K. C. Ng, Performance investigation of an advanced multi-effect adsorption, desalination (MEAD) cycle, Applied Energy 159 (2015) 469-477.

24. K.C. Ng, X.L. Wang, A. Chakraborty, in: Apparatus and Method for Desalination, 2006.

25. K.C. Ng, B.B. Saha, A. Chakraborty, S. Koyama, Adsorption desalination quenches global thirst, Heat Transfer Engineering, 29 (2008) 845-848. 
26. A. Li, K. Thu, A. B. Ismail, M. W. Shahzad and K. C. Ng, Performance of adsorbent-embedded heat exchangers using binder-coating method, International Journal of Heat and Mass Transfer, 92 (2016) 149-157.

27. M.Z.I. Khan, K.C.A. Alam, B.B. Saha, A. Akisawa, T. Kashiwagi, Study on a re-heat twostage adsorption chiller - The influence of thermal capacitance ratio, overall thermal conductance ratio and adsorbent mass on system performance, Applied Thermal Engineering, 27 (2007) 1677-1685.

28. M.Z.I. Khan, K.C.A. Alam, B.B. Saha, A. Akisawa, T. Kashiwagi, Performance evaluation of multi-stage, multi-bed adsorption chiller employing re-heat scheme, Renewable Energy, 33 (2008) 88-98.

29. K.C. Ng, K. Thu, B.B. Saha, A. Chakraborty, Study on a waste heat-driven adsorption cooling cum desalination cycle, International Journal of Refrigeration, 35 (2012) 685693.

30. K. Thu, K.C. Ng, B.B. Saha, A. Chakraborty, S. Koyama, Operational strategy of adsorption desalination systems, International Journal of Heat and Mass Transfer, 52 (2009) 1811-1816.

31. I. EI-Sharkawy, K. Thu, K. Ng, B. Saha, A. Chakraborty, S. Koyama, Performance improvement of adsorption desalination plant: experimental investigation, Int Rev Mech Eng, 1 (2007) 25-31.

32. K.C. Ng, X. Wang, Y.S. Lim, B.B. Saha, A. Chakarborty, S. Koyama, A. Akisawa, T. Kashiwagi, Experimental study on performance improvement of a four-bed adsorption chiller by using heat and mass recovery, International Journal of Heat and Mass Transfer, 49 (2006) 3343-3348.

33. K.C. Ng, K. Thu, G. Amy, M. Chunggaze, T.Y. Al-Ghasham, A Regenerative Adsorption Distillation System, in: WO Patent WO2012121675A1, 2012.

34. K.C. Ng, K. Thu, G. Amy, M. Chunggaze, T.Y. Al-Ghasham, An Advanced ADMED Cycle For Low-Temperature Driven Desalination, US Provisional Application No. $61 / 450,165$.

35. M.W. Shahzad, A. Myat, W.G. Chun and K.C. Ng, Bubble-assisted film evaporation correlation for saline water at sub-atmospheric pressures in horizontal-tube evaporator, Applied Thermal Engineering 50 (2013) 670-676. 
36. M.W. Shahzad, K.C. Ng, K. Thu, B.B. Saha and W.G. Chun, Multi effect desalination and adsorption desalination (MEDAD): A hybrid desalination method, Applied Thermal Engineering 72 (2014) 289-297.

37. K.C. Ng, K. Thu, A. Chakraborty, B.B. Saha and W.G. Chun, Solar-assisted dual-effect adsorption cycle for the production of cooling effect and potable water, International Journal of Low-Carbon Technologies 2009, 4, 61-67.

38. K.C. Ng, K. Thu and Y.D. Kim, Solar-assisted adsorption cycle for the production of cooling effect and potable water, 2nd European Conference on Polygeneration - 30th March-1st April, 2011- Tarragona, Spain.

39. O.A. Hamed, A.M. Hassan, K. Al-Shail and M.A. Farooque, Performance analysis of a trihybrid NF/RO/MSF desalination plant, Desal. Water Treatment, 1, 215-222 (2009).

40. K. Thu, Y.-D. Kim, G. Amy, W.G. Chun, K.C. Ng, A hybrid multi-effect distillation and adsorption cycle, Applied Energy, 104 (2013) 810-821.

41. K. Thu, Y.-D. Kim, G. Amy, W.G. Chun, K.C. Ng, A Synergetic Hybridization of Adsorption Cycle with the Multi-Effect Distillation (MED), Applied Thermal Engineering, 62 (2014) 245-255.

42. M.W. Shahzad, K. Thu, B.B. Saha and K.C. Ng, An Emerging Hybrid Multi-Effect Adsorption Desalination System, EVERGREEN Joint Journal of Novel Carbon Resource Sciences \& Green Asia Strategy, 01-02 (2014) 30-36.

43. K.C. Ng, K. Thu, M.W. Shahzad and W. Chun, Progress of adsorption cycle and its hybrids with conventional multi-effect desalination processes, IDA Journal of Desalination and Water Reuse, DOI 10.1179/2051645214Y.0000000020.

44. K.C. Ng, K. Thu, S.J. Oh, L. Ang, M.W. Shahzad and A.B. Ismail, Recent developments in thermally-driven seawater desalination: Energy efficiency improvement by hybridization of the MED and AD cycles, Desalination, 356 (2015) 255-270.

45. M.W. Shahzad, K. Thu, Y.D. Kim, K.C. Ng, An Experimental Investigation on MEDAD Hybrid Desalination Cycle, Applied Energy, 148 (2015) 273-281.

46. M.W. Shahzad, K. Thu, K.C. Ng and W.G. Chun, Recent development in thermally activated desalination methods: achieving an energy efficiency less than $2.5 \mathrm{kWh}$ elec $/ \mathrm{m}^{3}$, Desalination and Water Treatment, (2015) 1-10, doi: 10.1080/19443994.2015.1035499. 
47. M. W. Shahzad, The hybrid multi-effect desalination (MED) and the adsorption (AD) cycle for desalination, Doctoral Thesis, National University of Singapore, 2013. 


\section{$\underline{\text { List of Figures }}$}

Figure 1: Annual per capita renewable water resource in GCC countries between the years 1962 and 2010.

Figure 2: GCC cooling requirement from 2010-2030 [7]

Figure 3: Schematic diagram of the experimental apparatus.

Figure 4: Adsorption isotherms of parent Maxsorb III/ethanol pair.

Figure 5: Adsorption isotherms of $\mathrm{KOH}-\mathrm{H}_{2}$ treated Maxsorb III/ethanol pair.

Figure 6: Adsorption isotherms of MIL-101Cr/ethanol pair.

Figure 7: Plots of adsorption uptake and pressure versus time for MIL-101Cr/ethanol pair at adsorption temperature of $50^{\circ} \mathrm{C}$.

Figure 8: Arrhenius plot of the assorted adsorbent/refrigerant pairs.

Figure 9: A schematic of the hybrid MEDAD pilot.

Figure 10: Temperature profiles of MED and MEDAD components at heat source $50^{\circ} \mathrm{C}$

Figure 11: Water production profiles of MED and MEDAD cycles at heat source $50^{\circ} \mathrm{C}$. 


\section{Drying Up}

Nations around the Persian Gulf rely on imports and desalination to provide water to their growing populations. Annual renewable water resources per capita, in cubic meters":

WATER AVAILABLE IN 1962

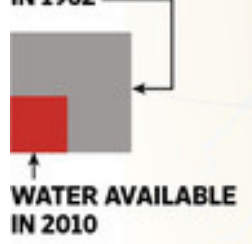

A country is considered to suffer from water scarcity if it has less than 1,000 cubic meters per capita.

Source: U.N. Food and Agriculture Organization The Wall Street Journal

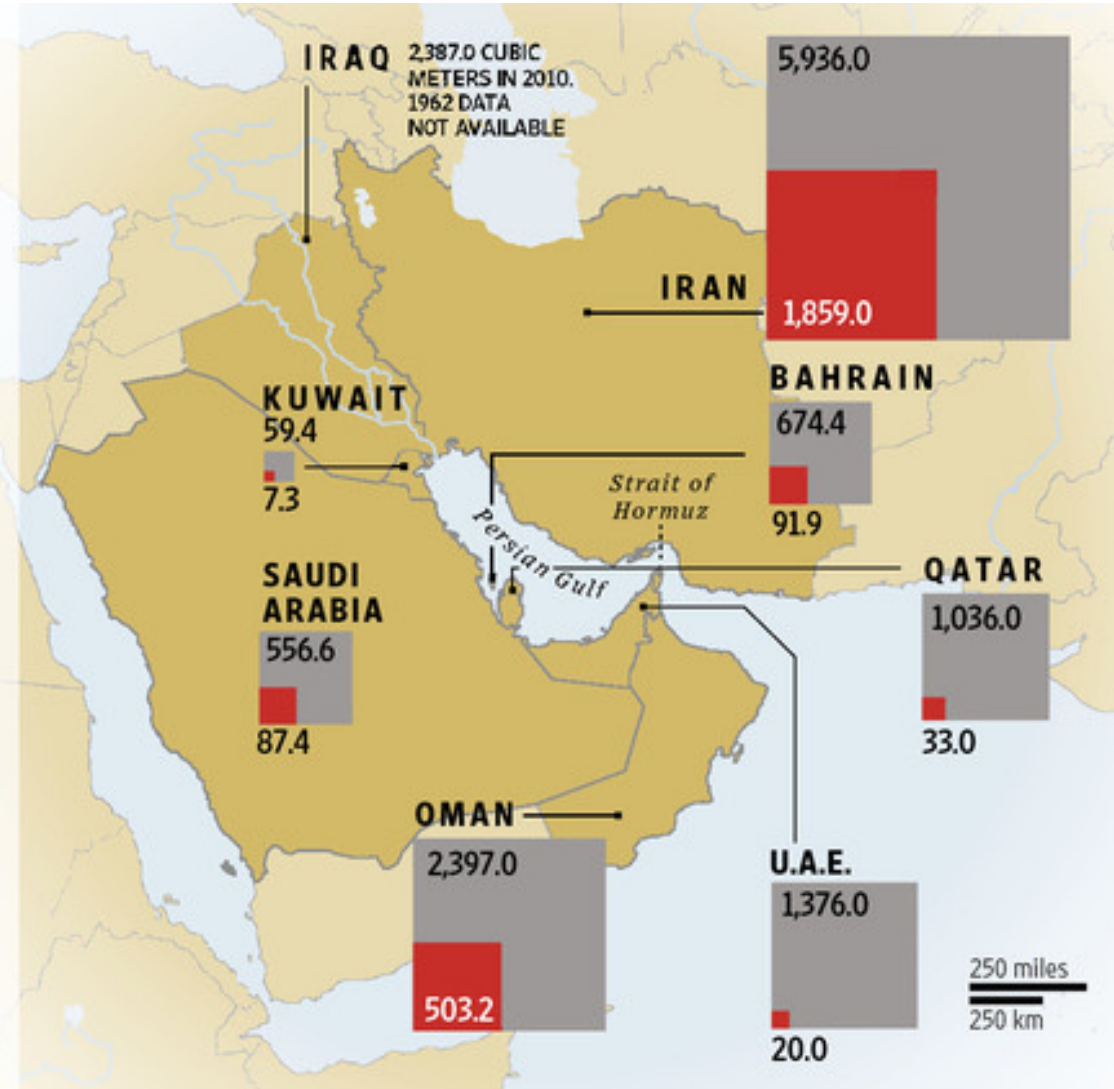

Figure 1: Annual per capita renewable water resource in GCC countries between the years 1962 and 2010 . 


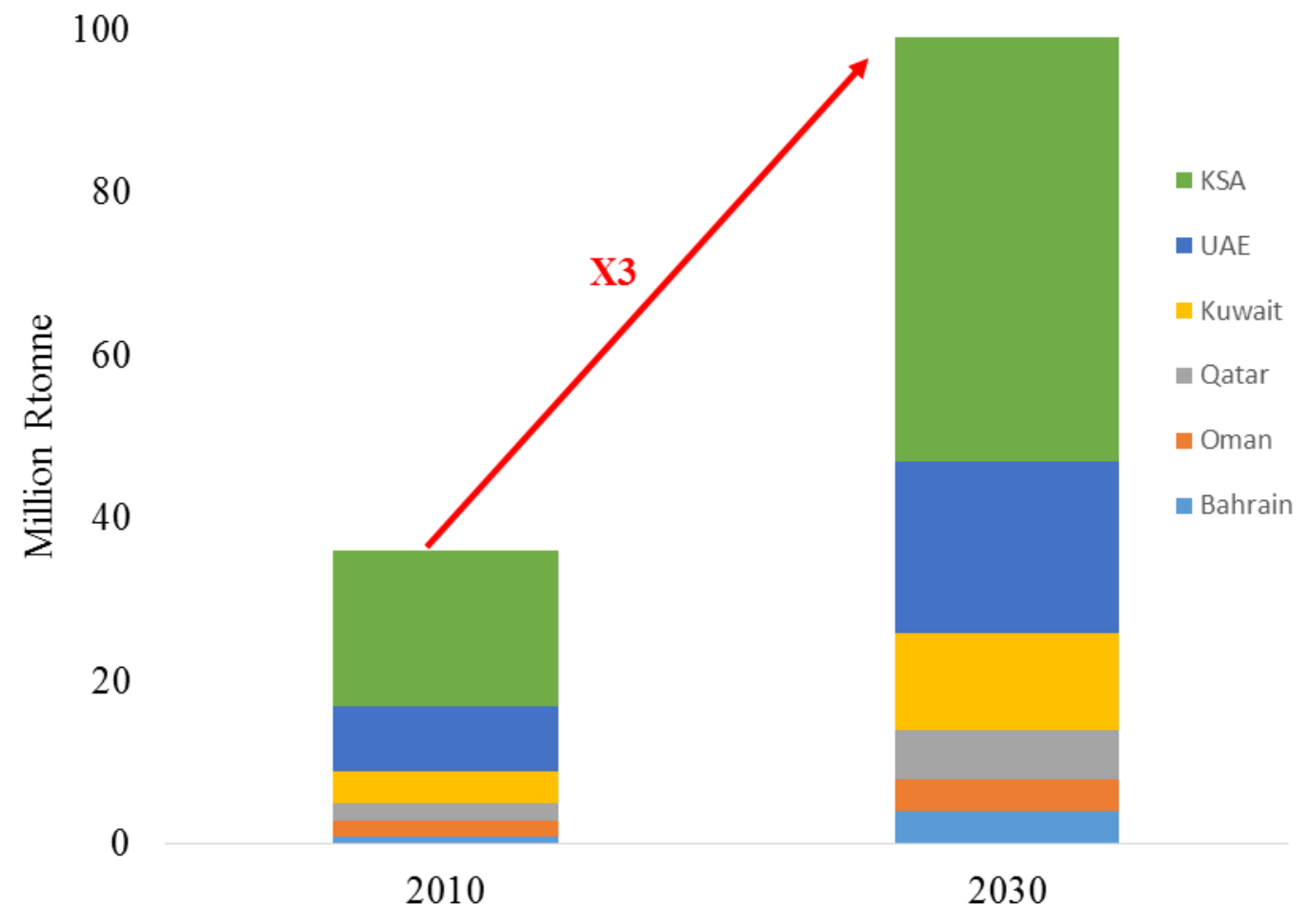

Figure 2: GCC cooling requirement from 2010-2030 [7]. 


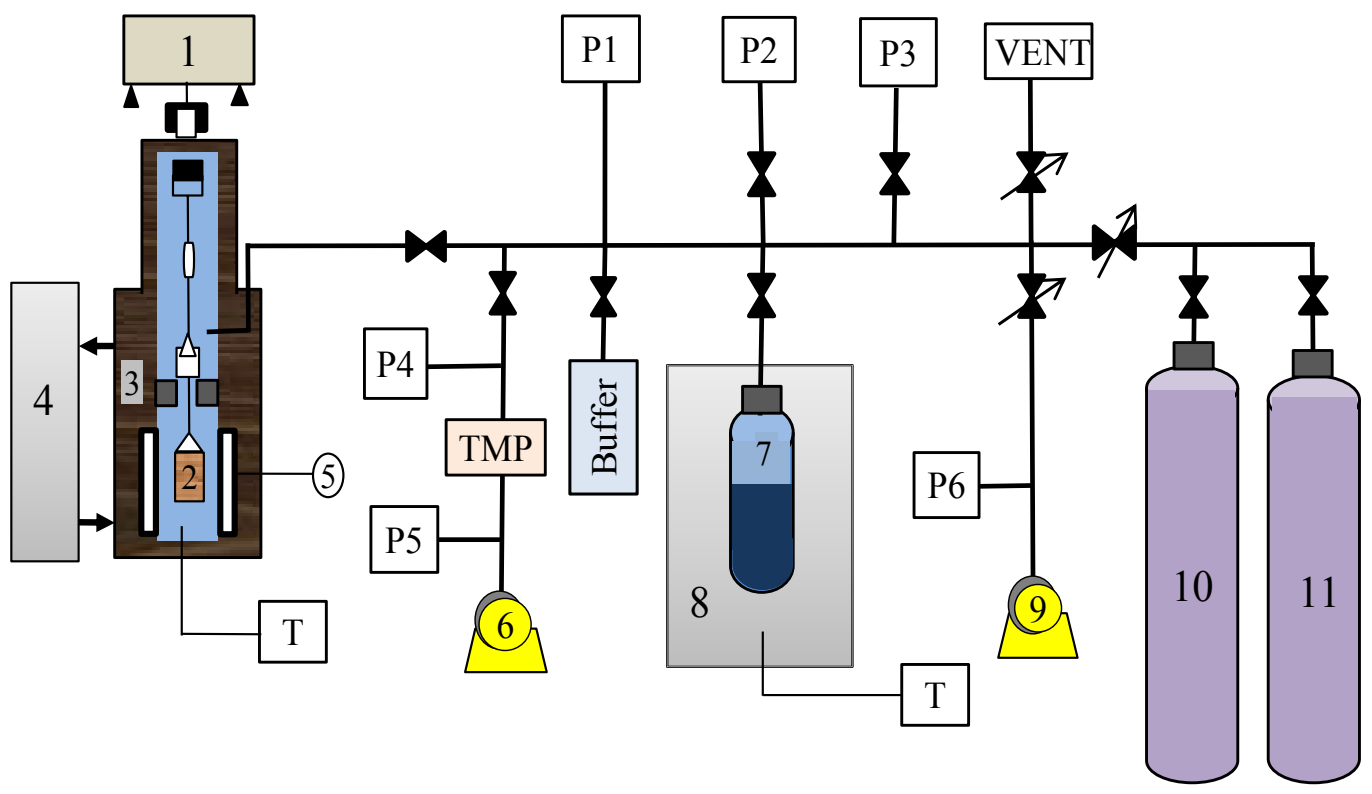

Figure 3: Schematic diagram of the experimental apparatus [12].

1. Magnetic suspension balance unit, 2.Sample cell, 3. Circulation oil jacket, 4. Isothermal oil bath, 5. Sheathed heater used during regeneration, 6, 9. Rotary and Diaphragm pump, respectively, 7. Refrigerant pool, 8. Isothermal oil bath, 10. Nitrogen, 11. Helium, TMP- Terbo-molecular pump, T- Thermocouple. P- Pressure gauge. 


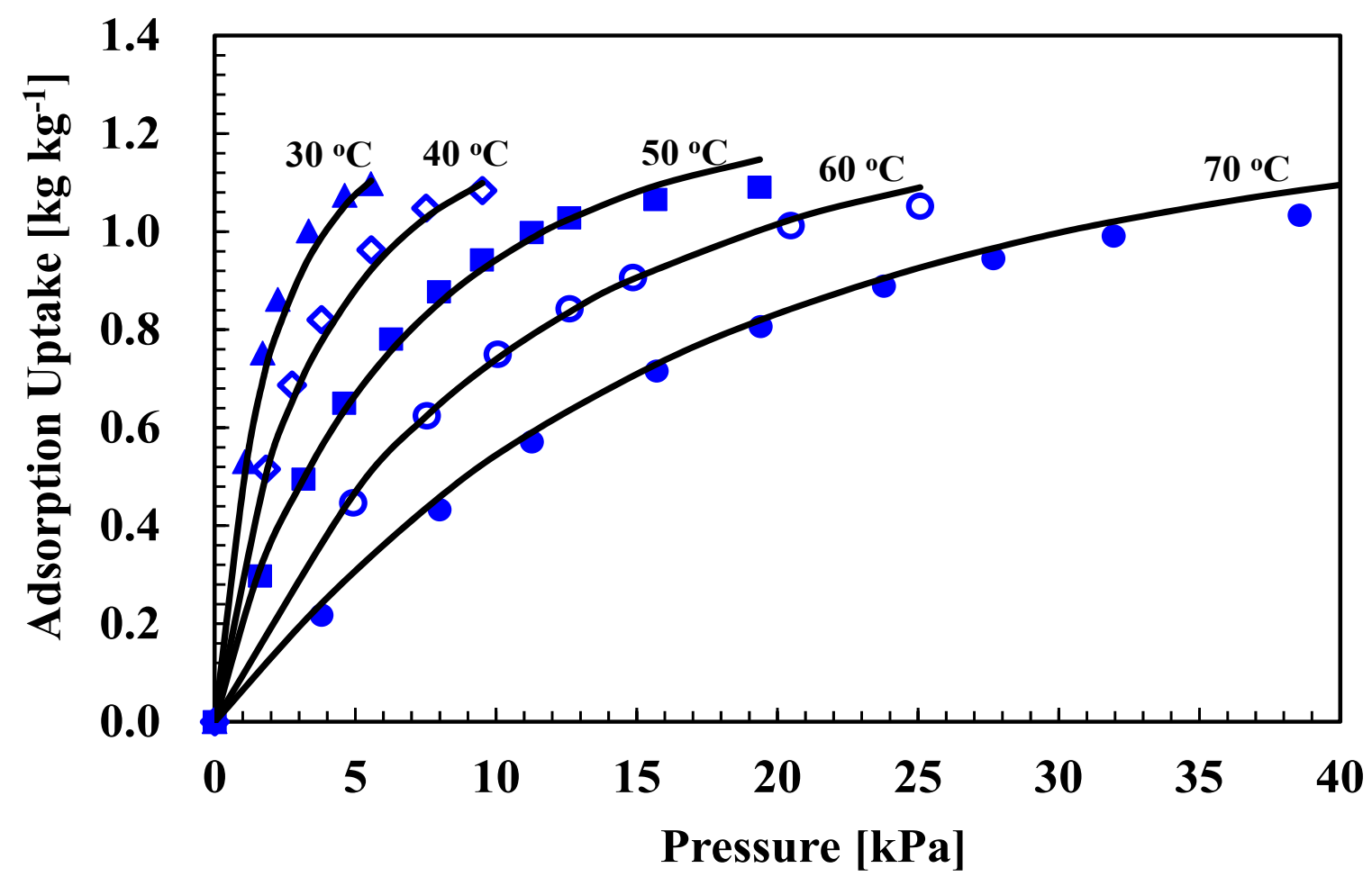

Figure 4: Adsorption isotherms of parent Maxsorb III/ethanol pair [12]. 


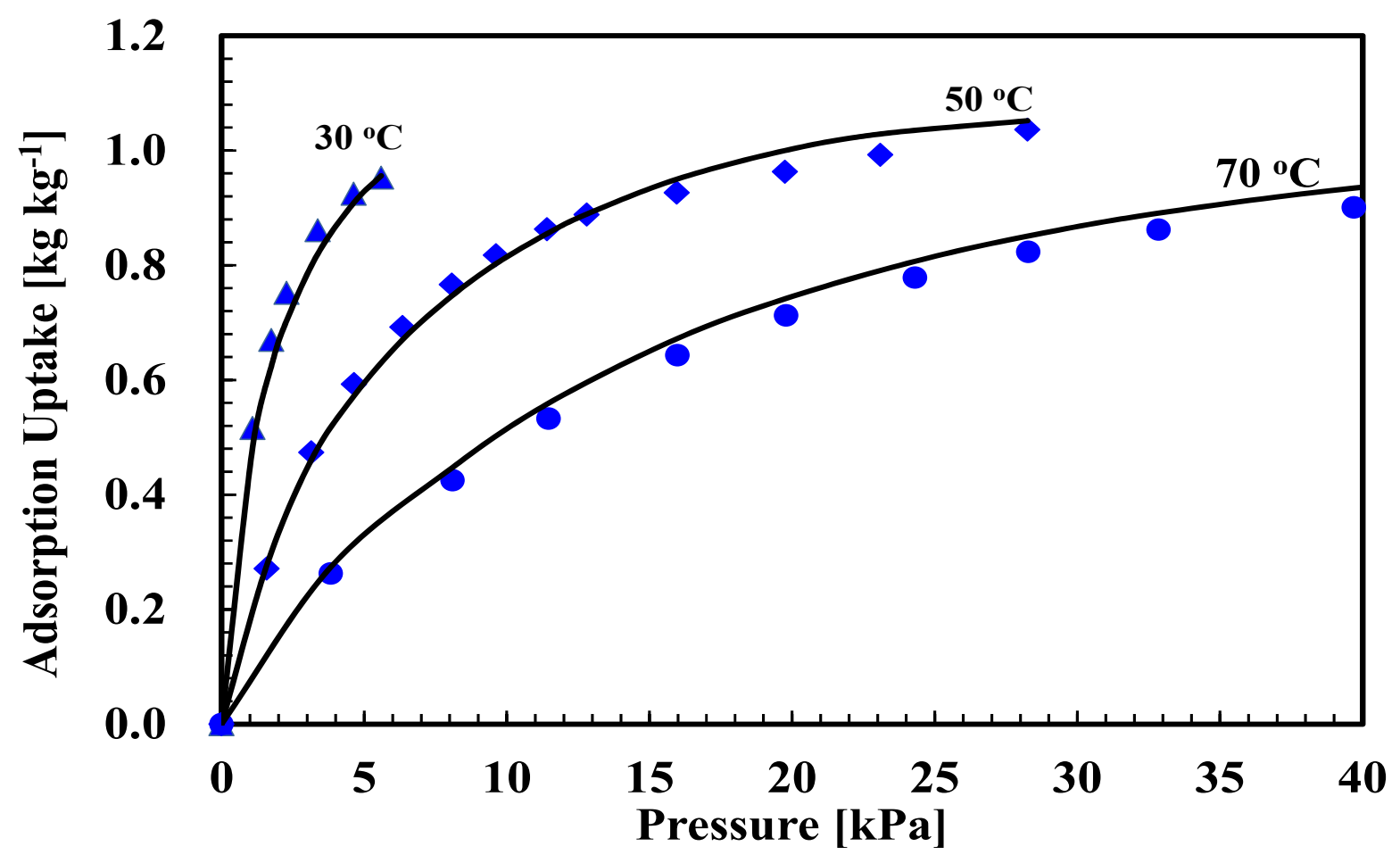

Figure 5: Adsorption isotherms of $\mathrm{KOH}-\mathrm{H}_{2}$ treated Maxsorb III/ethanol pair [12]. 

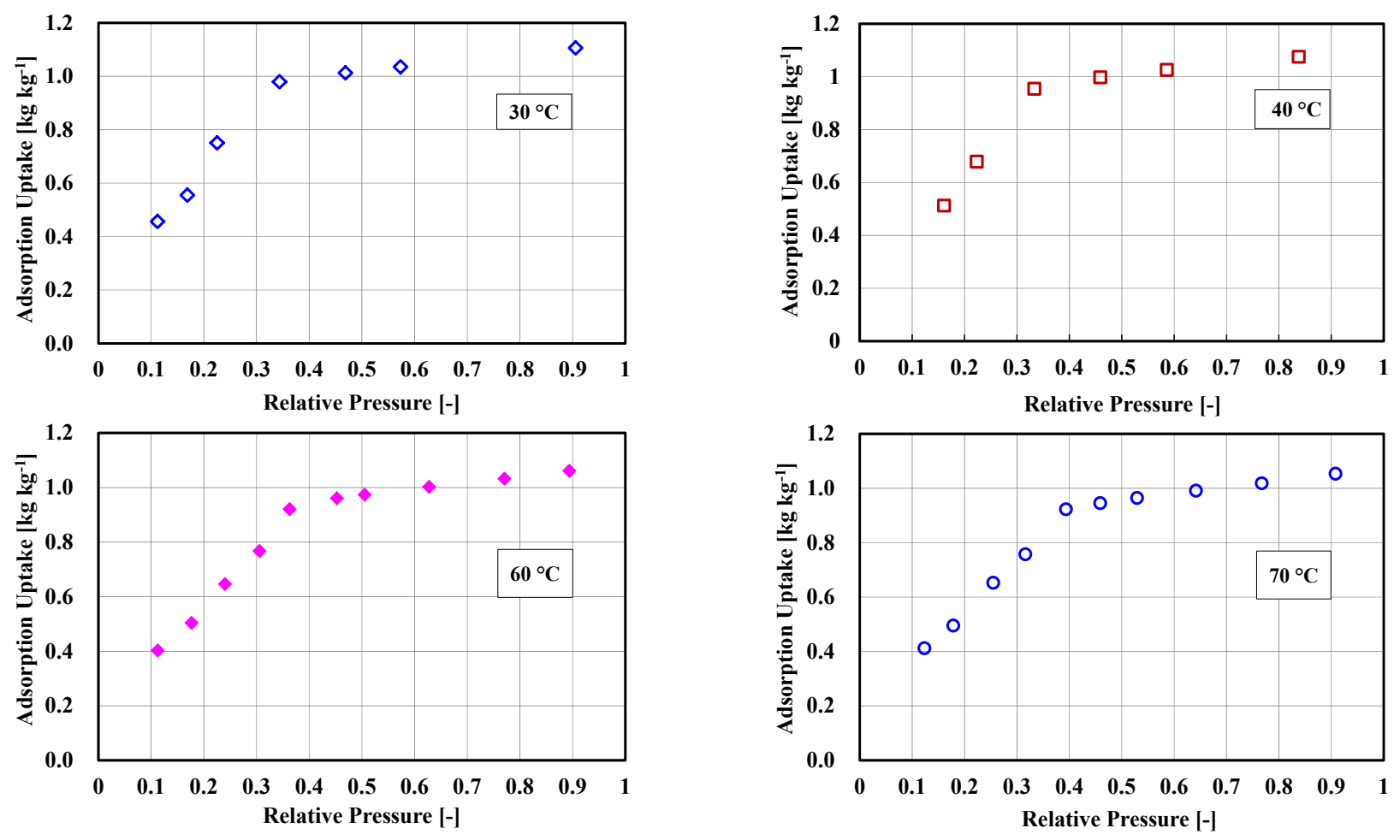

Figure 6: Adsorption isotherms of MIL-101Cr/ethanol pair [13]. 


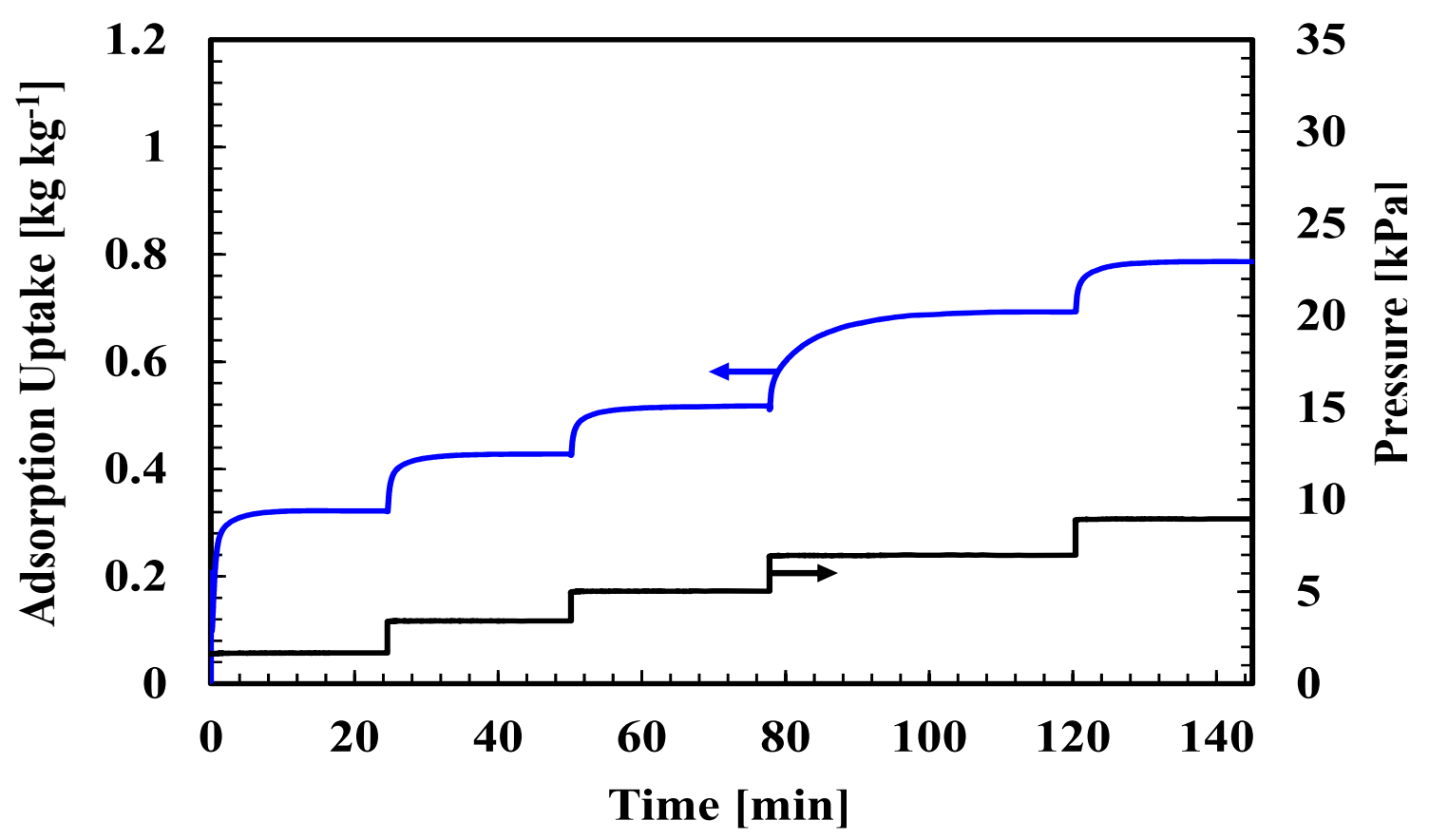

Figure 7: Plots of adsorption uptake and pressure versus time for MIL-101Cr/ethanol pair at adsorption temperature of $50^{\circ} \mathrm{C}$. 


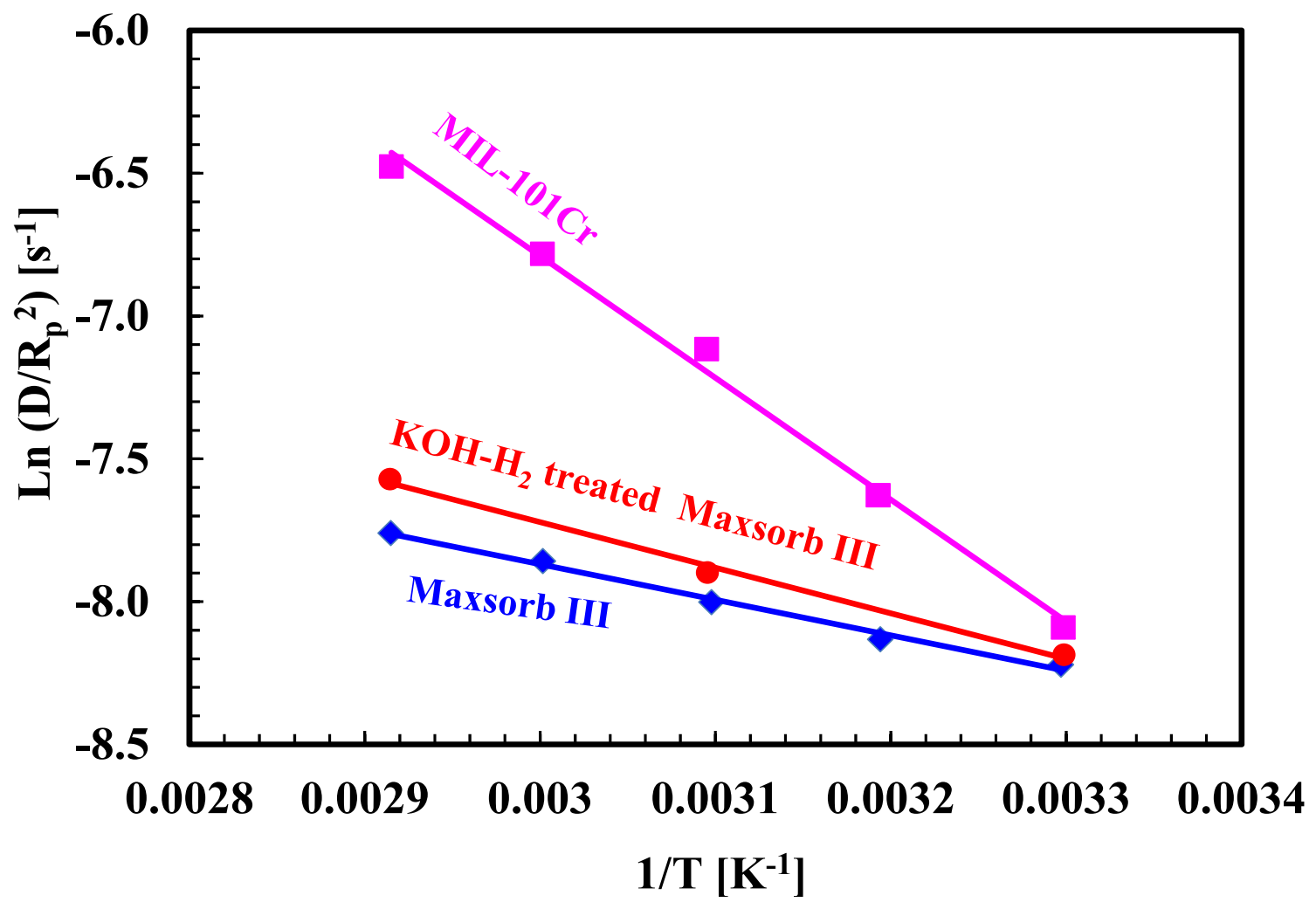

Figure 8: Arrhenius plot of the assorted adsorbent/refrigerant pairs. 


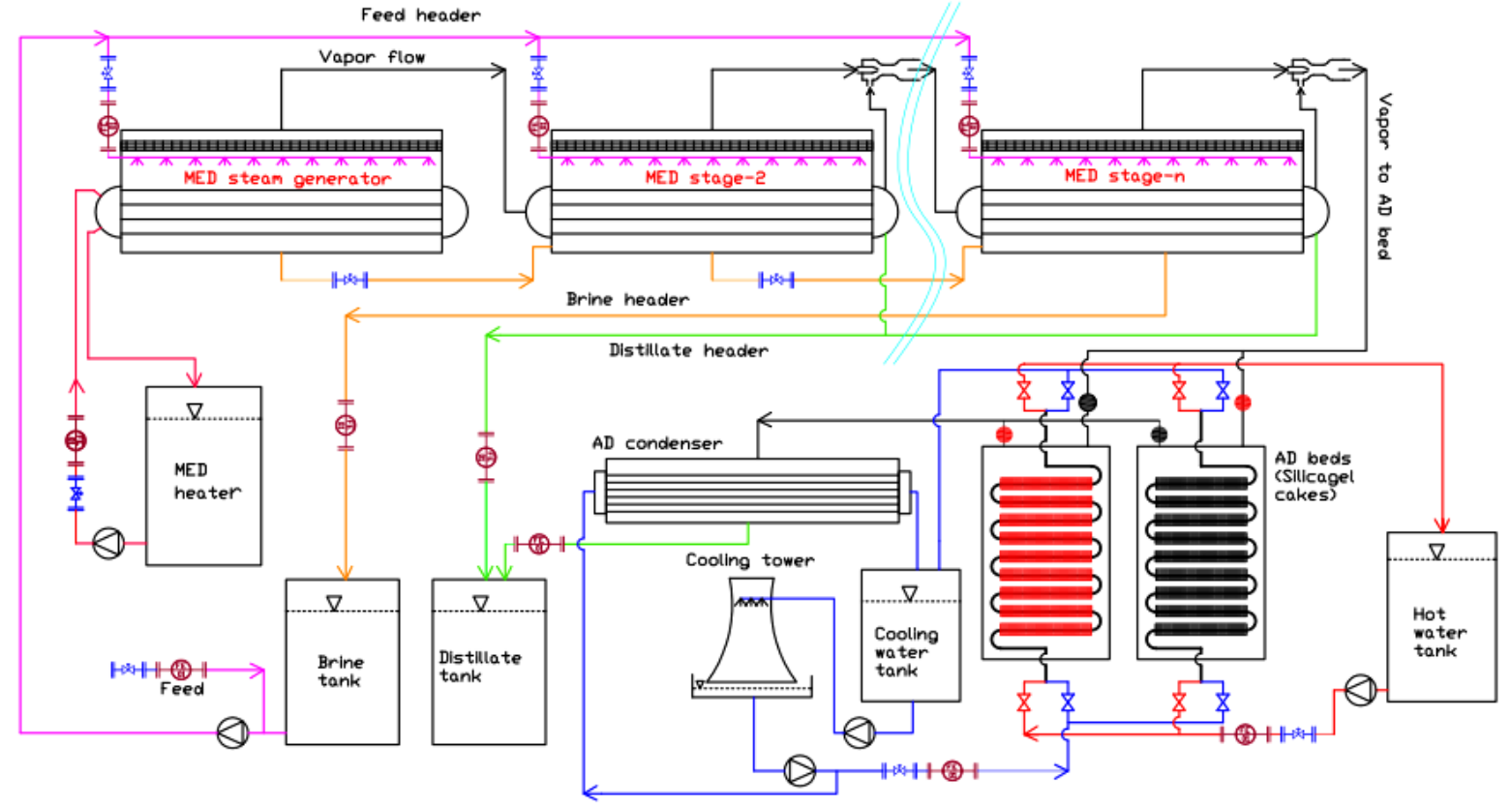

Figure 9: A schematic of the hybrid MEDAD pilot. 


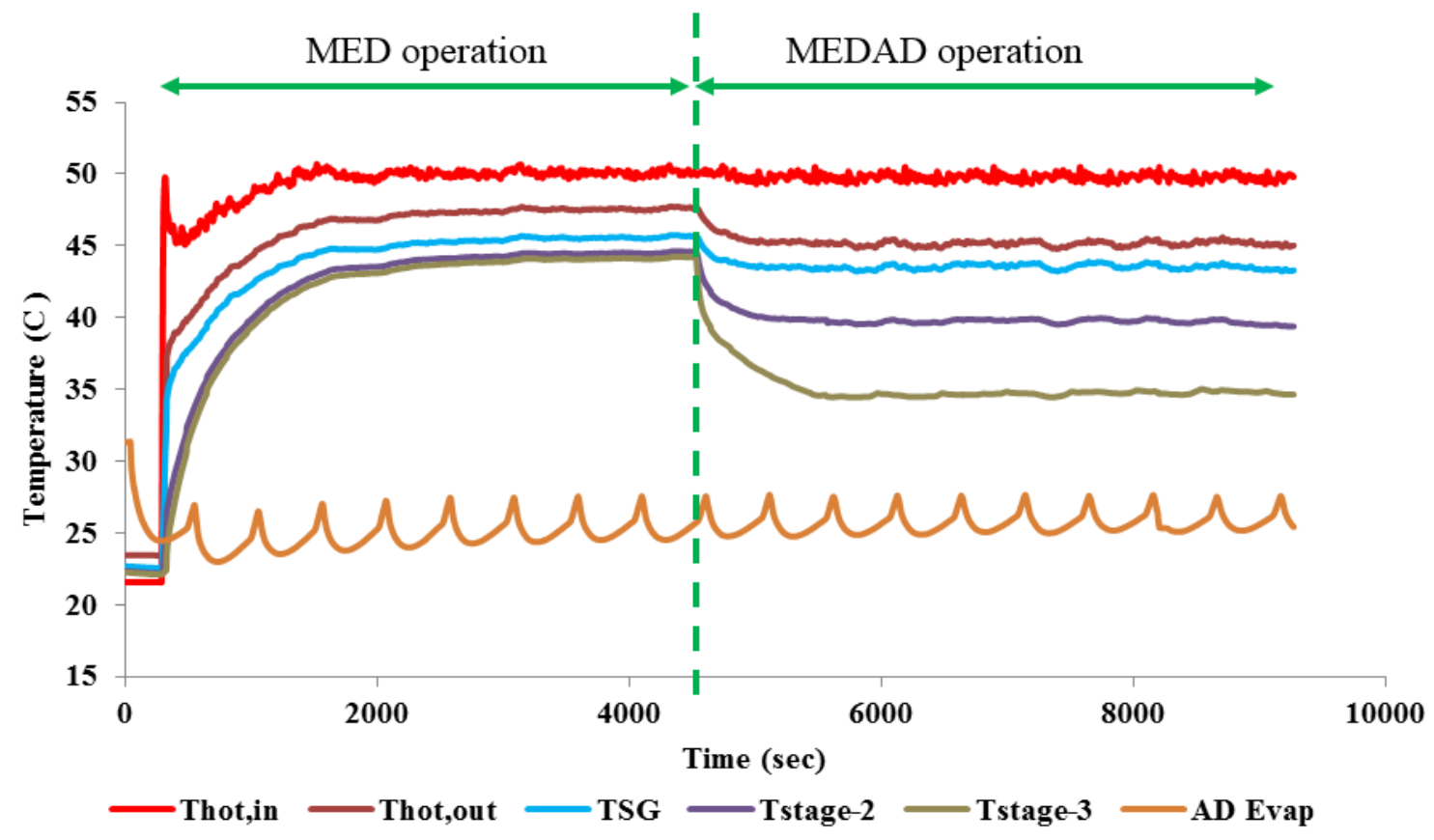

Figure 10: Temperature profiles of MED and MEDAD components at heat source $50^{\circ} \mathrm{C}$. 


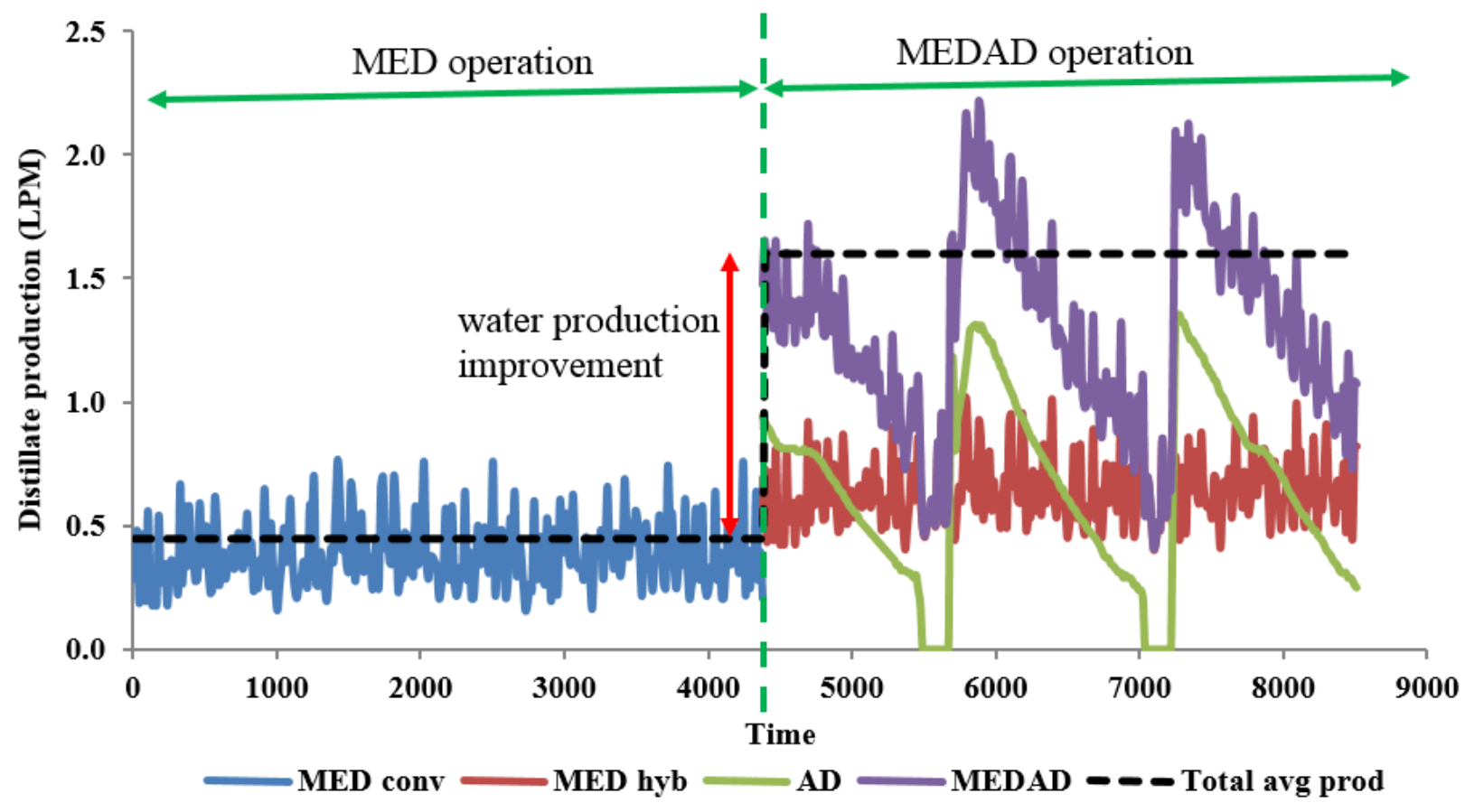

Figure 11: Water production profiles of MED and MEDAD cycles at heat source $50^{\circ} \mathrm{C}$. 


\section{List of Tables:}

Table 1: Projected water demand in GCC countries (millions of gallons). 
Table 1: Projected water demand in selected GCC countries (millions of gallons).

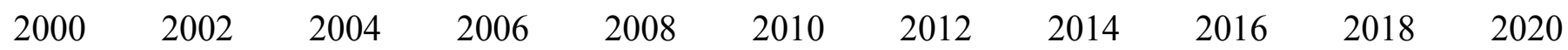

Country

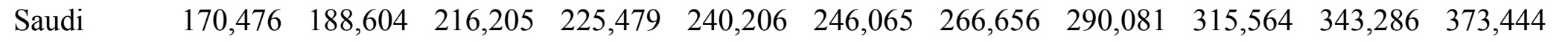

Arabia

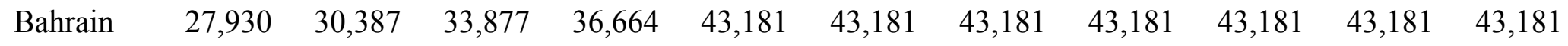

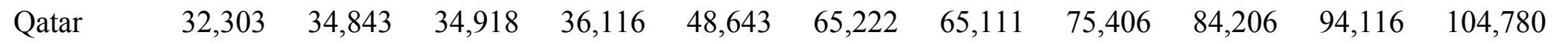

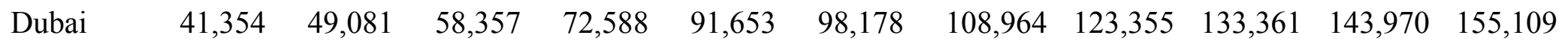

Sources: Saline Water Conversion Corp (Saudi Arabia); Electricity and Water Authority

(Bahrain); Qatar Statistics Authority; Dubai Water and Electricity Authority, EIU Estimates and Forecasts. 


\section{Graphical Abstract}

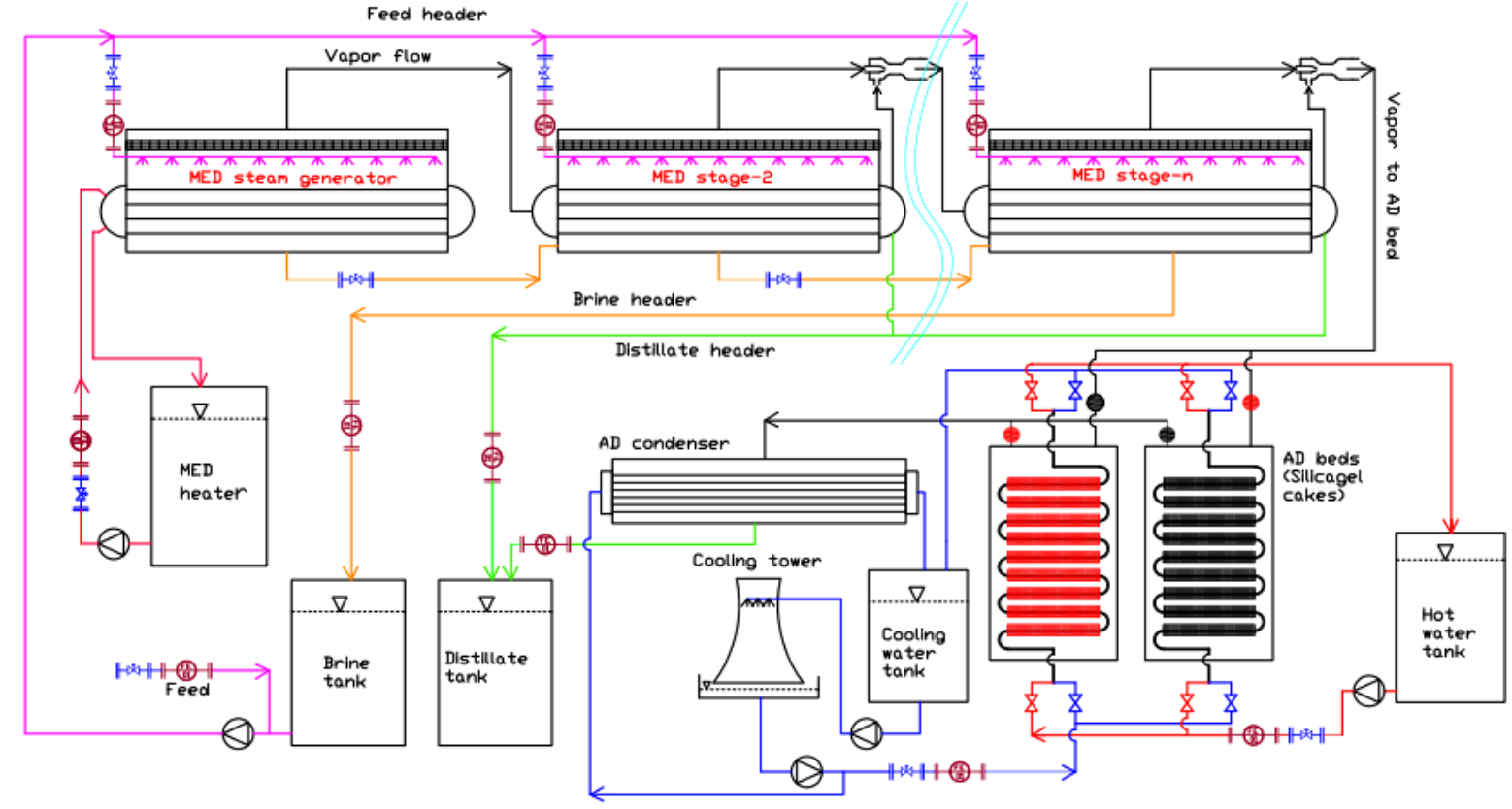

(a) Hybrid MEDAD pilot plan

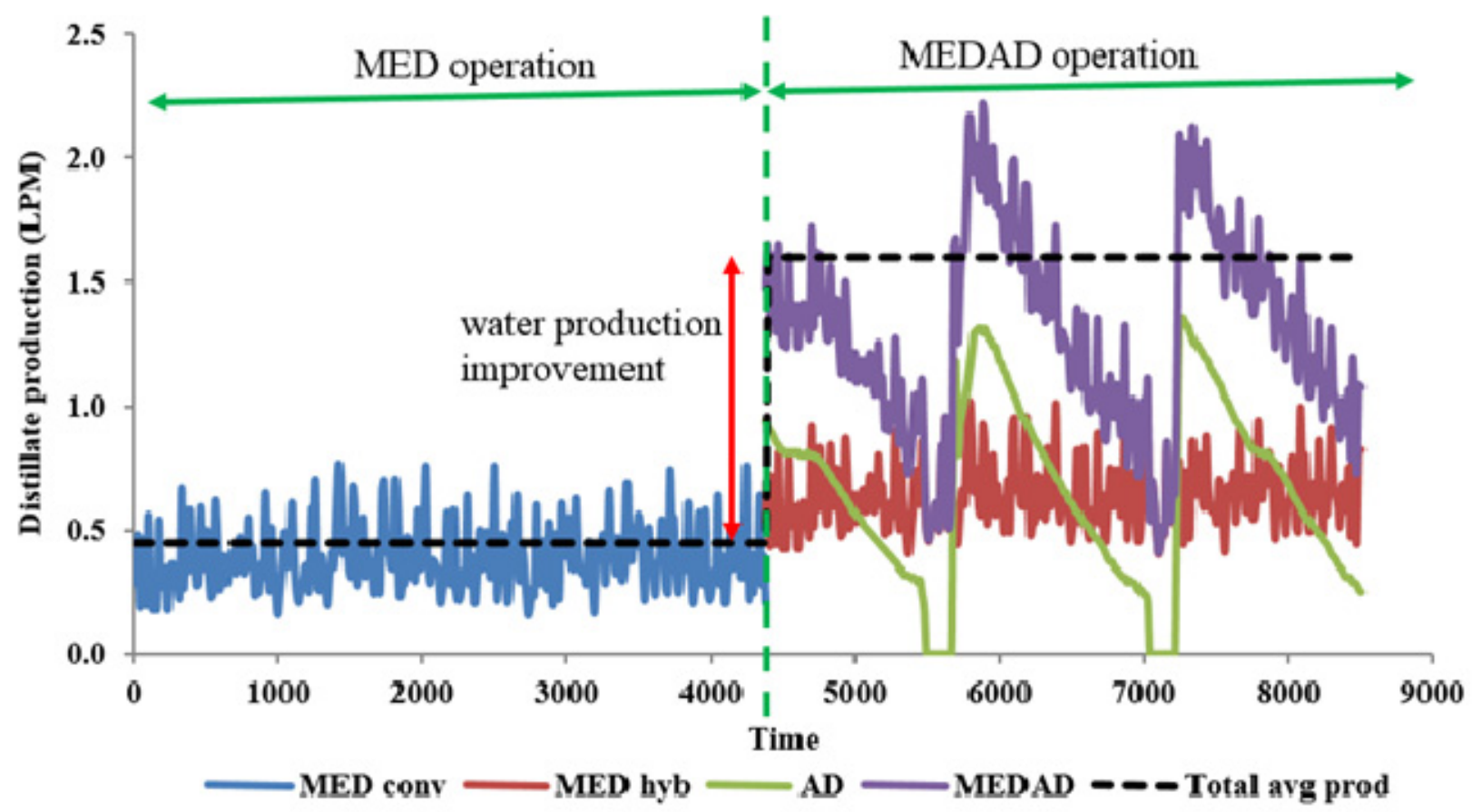

(b) Water production profiles of MED and hybrid MEDAD cycles

(a) Schematic of MEDAD cycle, and (b) water production profiles of MED and MEDAD cycles. 